\title{
A Suggested Professional Development Plan for Specialist Doctors Taking Leading Roles in the Establishment of Quality Healthcare
}

\author{
Ahmed Nadeem Abbasi* \\ Section of Radiation Oncology, Department of Oncology. The Aga Khan University, Karachi, Pakistan.
}

doi.org/10.21089/njhs.22.0049

\section{INTRODUCTION}

In modern healthcare centers physicians play an important and pivotal role in the establishment of quality health care systems and processes. One of the most important factor in professional development and growth of specialist is implementation of processes. I am postulating a plan for the consideration of specialist faculty colleagues.

A proposed Professional Development Plan (PDP) is being postulated in the following text. This proposed plan is being named as "The CART - 25\% plan", denoting the suggested proportion of skill development required for a specialist who is working towards a clear strategic vision This proposed plan is not expected to be a perfect plan which will be applicable on all individuals under all eventual circumstances, therefore appropriate modifications can be considered by an individual or a competent board of professionals who are designated to perform this task.

The CART plan is being stratified as:

1. Clinical (as per Professional Entity's Job Role).

2. Administrative.

3. Research.

4. Teaching.

Here, I would request the readers to assume that the professional is a specialist working in the capacity of a privileged medical specialist, professional is being used as an example in the following lines.

There are certain professional factual points for the consideration of any institutional core decision making body. It is in the wider and long term interest of the institution to make a jargon free clear like appraisal document which should include focused appraisal instead of long "fill in the blanks" style.

Institution can make this process of appraisal as a means of constant improvement in the PDP (Professional Development Plan) of an individual care giver. This is only possible if we avoid unnecessary paper work and jargon terms based lengthy forms.

Therefore following simplified CART based plan can be introduced and appraised with a view of constant improvement.

\section{CLINICAL (PROFESSIONAL COMMITMENT)}

The individual is expected to be focusing on a patient centered approach and needs to provide a document clearly defining the job role.

Monitoring via a "term based" briefing. This proposed professional development plan recommends avoidance of term assessment processes.

\section{ADMINSTRATIVE}

This particular area has its own importance and considered as an important component of the appraisal process. All administrative tasks and responsibilities will be pre designated by the board to individual staff member. All tasks will be documented in "job role" document and the accountability process will be based on "FAIR" foundations.

A designated time period will be pre-defined by the executive board for "ALL" administrative responsibilities. If due to any reason(s), the specified administrative responsibility will not be fulfilled up to a pre-set and pre-discussed minimum standard, a change in job role and/or person will be considered. This strategy will be a guarantee in progression of modernization standards. Managerial skills development is regarded as the essential tool for all healthcare decision makers and specialist doctors are not an exception. After going through various practical day to day managerial issues, I would be inclined to recommend the following list of skills which need to be learned via interactive sessions facilitated by experts in their respective fields of management sciences. A specialist doctor has to play the role of a manager with administrative responsibilities. If the managerial skills are fully developed an specialist can interact effectively with 
problems encountered in the establishment and delivery of modern healthcare.

The executive board can take a direct regulatory role in terms of implementation of these skill development learning sessions. The list is given as follows:

1. Managerial interactions.

2. Communication skills.

3. Negotiation skills.

4. Time management.

5. Change management.

6. Implementation of quality in health care.

7. Conflict resolution.

8. Assertiveness without aggression.

9. Goal setting.

10. Leadership skills.

11. Economic evaluation models.

12. Team building.

13. Caring the corers.

14. Training the trainers.

It can be designated as a mandatory responsibility of the human resource development section to make sure that required skills are being inculcated to all individuals who will be playing a definitive role in the planning processes of all aspects of organizational issues. I can expect a positive change in staff members who will go through the above mentioned skill development workshops.

\section{RESEARCH}

In developing countries, this part of the professional development plan merits prime attention of planners. Requirement of pre-set standards as per international guidelines will be our main objective. Some flexibility may be exercised in the first few months of the appointment as research culture is not very well established in the country. The institute can take leadership role and can act as a trend setter of "relevant" research geared towards getting answers to loco-regional patient care needs. An example which can be quoted is; research towards high quality cost efficient evidence based practices, which can be prioritized in academic institution. Regular academic session should be conducted and active participation should be monitored via quarterly or bi-yearly appraisals.

\section{TEACHING}

Instead of giving a fish to some deserving person, it is more advisable to teach them how to do fishing. An apprenticeship styled teaching can only lead to the production of ill-trained followers and not leaders, resulting in visionless doctors who will not be able to deliver modern specialist health care to their patients. Contribution towards the professional growth and development of colleagues will be structured as an integral component of institutional goals. Appraisal process will make sure that efficient and effective implementation of educational tasks is being met as per minimum standards and bench marks are being set in job role documents. One cannot emphasize more on this subject of skill development training delivered via the most modern educational methodology. I would recommend adaptation of structured teaching as a component of learning objective, which is the base of professional development and growth program.

\section{General Considerations}

In order to implement the above mentioned proposed "CART" plan a thorough briefing of each component of four sections should be performed before the date of commencement of new appraisal term. If we fail to plan well then our plan will fail. We would suggest a two phase briefing session, which can be performed at the time of drafting phase of the plan. Once all components of CART (which are mentioned in the four sections), are being discussed and endorsed by the individual professional colleagues, one can set a fixed term for interim midway appraisal. Most of the institutes follow an annual appraisal scheme, we would suggest a six monthly appraisal duration term with the provision of an interim appraisal, to be performed after three months of commencement of this plan.

Designated responsibilities in a professional plan can be narrated as specialized roles which focus particularly on a specified domain. [1] In this proposed plan the domains are broadly classified under the heading of four broad divisions.

Components and contents of structured CART plan can vary from one specialty to another. A flexible all inclusive approach is being recommended as innovations always attract teething issues during the initialization phase. Optimization of resource allocations is also a subject of great interest in the process of setting up directions for the healthcare professionals [2].

The provision of a patient centered healthcare quality is the aim and objective of an ideal professional growth plan. At the time of planning an accurate understanding of the quality management system is required. A team of dedicated professionals will take the responsibility of implementing this plan, which is an actual fact a component of the quality improvement process. Collaborative efforts are required in order to achieve this goal [3]. Some special aspects of healthcare quality are applicable as pivotal moving factors in Low and Middle Income Countries (LMIC). Economic evaluation models are being studied in great depth and their complexities also play some detrimental roles in the development of 
an individual's professional career growth. Only cost effective options of healthcare provision can be administered and implemented in countries with limited resources [4]. While going through contemporary literature published on this subject, we came across some factual narrations addressing the issue of quality from various aspects. Communication skills and standards of conduct are being nominated as important factors of relevance in quality improvement process of professional development [5].

This CART plan is being proposed for specialists belonging to all specialties of health care and this plan will be more appropriate for LMIC where care providers have more administrative role.

\section{The Ideal CART plan}

Taking the above mentioned postulated plan further, I would like to propose an arbitrary ideal CART plan which is being based on an equally distribution of tasks among all four components which are clinical, administrative, research and teaching. On the basis of this proposed ideal situation, I am naming it as "The CART $-25 \%$ plan" of professional development. We have to agree to disagree, this ideal situation does not exist in reality, that is why, I am leaving this argument open ended and would be glad to entertain criticism and open disagreement without any reservations. We have to ask from ourselves, that are we delivering the right optimal services to our patients and what is our strategic visioning of future developments in our own territory? Once we agree on a plan in principle, the proportion of time and tasks can be discussed during the subsequent briefing sessions. No one can force us to adopt a plan without knowing the consequences and outcome. Therefore, it is imperative to start with a set proportion of all four components of the CART plan, as per our own understanding and requirements. I do appreciate that my postulated $25 \%$ equal proportioned CART plan may not be an agreeable option for most of my professional colleagues. Let us agree to disagree and I wish to stand firm on my postulate of CART with $25 \%$ i.e. a quarter equally partitioned four quadrants, offering equal importance to clinical, administrative, research and teaching responsibilities. We shall at least agree to call this equal proportionate CART plan as "The ideal CART plan".

\section{CONFLICT OF INTEREST}

Declared none.

\section{ACKNOWLEDGEMENT}

Dr. Arifa Aziz made changes as per comments suggested by the reviewers.

\section{REFERENCES}

[1] De Bont A, Exel J, Coretti S, Okem Z, Janssen M, Hope K, Ludwicki T, Zander B, Zvonickova M, Bond C, Wallenburg I, MUNROS Team. Reconfiguring health workforce: a case-based comparative study explaining the increasingly diverse professional roles in Europe. BMC. Health Serv. Res., 2016; 16(1): 637. DOI: 10.1186/s12913-016-1898-0

[2] Montague T, Gogovor A, Marshall L, Cochrane B, Ahmed S, Torr E, Aylen J, Nemis-White J. Searching for best direction in healthcare: distilling opportunities, priorities and responsibilities. $J$. Healthc. Q., 2016; 19(3): 44-49. DOI: 10.12927/hcq.2016.24867

[3] Camargo-Borges C, Moscheta M. Health 2.0: Relational resources for the development of quality in health care. Health Care Anal., 2016; 24(4): 338-348. DOI: 10.1007/s10728-014-0279-2

[4] Abbasi AN. Development of cancer services: potential specific complexities in the perspective of health economic evaluation. $J$. Coll. Physicians Surg. Pak. 2013; 23(3): 171-2. DOI: 03.2013/JCPSP. 171172

[5] Steven K, Angus A, Breckenridge J, Davey P, Tully V, Muir F. Identifying key areas for active inter professional learning partnerships; a facilitated dialogue. J. Inter. Prof. Care. 2016; 30(6): 826-828. DOI: 10.1080/13561820.2016.1218829 